\title{
Animal Models for Fibrotic Liver Diseases: What We Have, What We Need, and What Is under Development
}

\author{
Bénédicte Delire ${ }^{1}$, Peter Stärkel ${ }^{1,2}$ and Isabelle Leclercq*1 \\ ${ }^{1}$ Laboratory of Hepato-Gastroenterology, Institut de Recherche Expérimentale et Clinique (IREC), Catholic University of Louvain \\ (UCL), Brussels, Belgium; ${ }^{2}$ Department of Gastroenterology, Saint-Luc Academic Hospital and Institute of Clinical Research,
} Catholic University of Louvain, Brussels, Belgium

\begin{abstract}
Liver fibrosis is part of the wound-healing response to liver damage of various origins and represents a major health problem. Although our understanding of the pathogenesis of liver fibrosis has grown considerably over the last 20 years, effective antifibrotic therapies are still lacking. The use of animal models is crucial for determining mechanisms underlying initiation, progression, and resolution of fibrosis and for developing novel therapies. To date, no animal model can recapitulate all the hepatic and extra-hepatic features of liver disease. In this review, we will discuss the current rodent models of liver injuries. We will then focus on the available ways to target specifically particular compounds of fibrogenesis and on the new models of liver diseases like the humanized liver mouse model.
\end{abstract}

(C) 2015 The Second Affiliated Hospital of Chongqing Medical University. Published by XIA \& HE Publishing Ltd. All rights reserved.

\section{Introduction}

Fibrosis is part of the general wound-healing response to liver damage of various origins and is defined by the accumulation and qualitative changes in extracellular matrix (ECM) components. The hepatic stellate cell (HSC) is the main cellular effector of this phenomenon and the major producer of scar ECM. $^{1}$

Liver fibrosis remains a major health problem as fibrotic liver diseases have a high mortality rate and predispose to liver failure, portal hypertension, and hepatocellular carcinoma (HCC). ${ }^{2}$ Although intense research during the last 20 years has led to considerable improvements in the understanding of liver fibrosis pathogenesis, effective antifibrotic therapies are still lacking. A better understanding of the mechanisms implicated in the initiation, progression, and resolution of fibrosis is crucially needed. Animal models are essential to study the processes underlying fibrogenesis, to identify potential therapeutic targets, and to evaluate the impact of antifibrotic therapies. ${ }^{3}$ Larger animal (rabbit, dog, chimpanzee, etc.) may be used, but rodent (mouse and rat) models are preferred and best standardized. ${ }^{4}$

When using animal models, one must keep in mind some general concepts, advantages, and pitfalls. A Gold Standard Publication Checklist (GSPC) was published in 2010 to improve the quality of animal studies and related publications and the feasibility of systematic reviews. ${ }^{5}$ GSPC directly benefits animal welfare and should be taken into account by all investigators when planning an experimental design. In studies on liver fibrosis, reproducibility, specificity, feasibility, optimal number of animals (to eliminate individual heterogeneity), and opportunity to largely sample the liver (to avoid sampling error) must be considered. ${ }^{6}$ The rodent strain is also of importance given large variations in fibrosis susceptibility related to the genetic and immunologic background. $^{3}$

Compared to clinical research, the use of animal models offers several advantages: (i) the possibility to collect multiple samples at different time-points and to realize sequential studies, (ii) a shorter time for disease development, (iii) the ability to control and reduce variables that cannot be closely followed in humans, and (iv) the ability to study the implication of specific genes/signaling pathways by the use of genetically modified animals. Moreover, compared to in 
vitro systems, animal models allow for the study of the liver as a complete organ, with intact and dynamic cell-cell and cell-matrix interactions and intact crosstalk of the liver with the entire body, including immune, vascular, metabolic, and endocrine interactions. ${ }^{6}$

Unfortunately, animal models are not the panacea to resolve all questions. Because animals are not humans, they do not develop human diseases. Large variations in responses to noxious agents exist between humans and animals regarding pathogenicity, timing, and immunoinflammatory reactions. ${ }^{6}$ Differences between humans and animals reside at several levels. First, some hepatic diseases do not exist in rodents. For example, the hepatitis $C$ virus (HCV) does not infect rodent hepatocytes; chimpanzees and Tupaia belangeri (a Northern tree shrew) are the only animals that support HCV infection, although they do not develop chronic liver disease and fibrosis. ${ }^{7}$ Second, animals may be less or more susceptible to toxic agents than humans. Alcoholic liver disease (ALD) is particularly difficult to induce in rodents. They have a total aversion to alcohol, and rapid alcohol metabolism prevents high blood alcohol levels. Moreover, even in animals continuously and chronically fed alcohol by intragastric infusion (Tsukamoto-French model), severe liver fibrosis does not develop, arguing for a different susceptibility to alcohol toxicity between animals and humans. ${ }^{8}$ In contrast to alcohol, common bile duct ligation $(\mathrm{CBDL})$ results in secondary biliary cirrhosis after only a few weeks in rodents, whereas month-long impairment of the bile flow is needed to cause severe liver fibrosis in humans. Finally, some liver pathology occurs in a specific metabolic or immune context, like non-alcoholic steatohepatitis (NASH) and autoimmune hepatitis (AIH), or is strongly associated with particular clinical entities, like primary sclerosing cholangitis (PSC), which is preferentially observed in patients suffering from inflammatory bowel disease. To date, no animal model recapitulates complex hepatic and extra-hepatic features and succeeds in modeling intricate diseases.

To increase our understanding of human liver disorders, animal models that replicate specific disease mechanisms or the disease as a global entity, including metabolic and immune aspects, and tools able to target specific cells, components of the ECM, or signaling pathways, are valuable. In the first part of this review, we will briefly discuss the current animal models in use for liver injuries, with emphasis on fibrosis progression and translational aspects. In the second part, we will focus on the available tools that target specifically one particular element involved in fibrogenesis. These tools include the use of genetically modified animals, cell-tracking/labelling methods, and targeted delivery systems. Finally, we will discuss new models of liver disease, like the humanized mouse, and its potential applicability in the field of liver fibrosis.

\section{Animal models of liver diseases}

The use of animal models for experimental liver fibrosis research has been extensively discussed previously. ${ }^{6,9}$ They are listed in Table 1 . We will briefly highlight their main features and interesting specificities and provide relevant information for translation of experimental findings from animals to humans.

\section{Hepatotoxin-induced liver fibrosis as a model of postnecrotic fibrosis (Table 2)}

Carbon tetrachloride $\left(\mathrm{CCl}_{4}\right)$, thioacetamide (TAA), dimethylnitrosamine (DMN), and diethylnitrosamine (DEN) are the most commonly used toxic agents to induce liver fibrosis in rodents. These toxins are mainly metabolized by centrilobular hepatocytes and cause centrilobular liver damage. The resulting fibrosis first appears in the perivenular area. As fibrosis extends, bridges between central areas are formed, with portal areas being secondarily involved (portal-central septa). Importantly, in humans, fibrosis is more frequently distributed in periportal and lobular areas and central fibrosis such as caused by hepatotoxins is only seen in hemodynamic or vascular disorders, i.e. chronic right ventricular dysfunction or chronic Budd-Chiari syndrome.

The $\mathrm{CCl}_{4}$-induced model of liver fibrosis is a widely used and studied, reliable animal model of hepatic fibrosis. ${ }^{10}$ Repeated doses of $\mathrm{CCl}_{4}$ lead to repeated rounds of woundhealing, causing HSC activation, imbalance between ECM production and degradation, and development of progressive hepatic fibrosis. ${ }^{6}$ Multiple protocols for $\mathrm{CCl}_{4}$ administration in mouse and rat are described in the literature, which vary in terms of route of administration (intraperitoneal (ip) injections, subcutaneous (sc) injections, oral gavage, and inhalation), dosage, adjustment of the initial dosage to daily/ weekly change in body weight, frequency of dosing, duration, dilution of $\mathrm{CCl}_{4}$, nature of the vehicle (olive oil, corn oil, paraffin oil, etc.), and the eventual use of phenobarbitone in the drinking water as enzyme inducer. ${ }^{11}$ In addition to these parameters, the susceptibility of a given animal strain, depending on immunologic background, affects efficiency and severity of liver fibrosis development. ${ }^{12-14}$ The impact of immune status is illustrated by variation in the severity of fibrosis following $\mathrm{CCl}_{4}$ administration observed (i) in Balbc and $\mathrm{C} 57 \mathrm{BL} / 6$ mice due to a different Th1/Th2 cytokines response ${ }^{13}$ and (ii) in wild-type Balbc mice, severe combined immunodeficiency (SCID) mice (lacking $B$, T cells but having NK cells), and SCID beige (lacking B, T and NK cells) mice. ${ }^{15}$

Repeated (ip injections) or chronic (supplementation in drinking water) TAA exposure leads to severe fibrosis/ cirrhosis between 12 and 16 weeks in rats and between 16 and 24 weeks in mice. ${ }^{16,17}$ Compared to $\mathrm{CCl}_{4}$-induced cirrhosis, TAA is associated with more prominent regenerative nodules and rapid development from periportal fibrosis to a state resembling human cirrhosis. ${ }^{18}$ While $\mathrm{CCl}_{4}$-induced liver fibrosis reverses in a short time, ${ }^{19}$ fibrosis persists for more than 2 months after TAA withdrawal, ${ }^{16}$ making these models complementary for studying processes of fibrosis reversal. Moreover, $\mathrm{CCl}_{4}$ fibrosis develops linearly, ${ }^{6}$ whereas with TAA, fibrogenesis initiation is slow, followed by a sudden exponential acceleration of matrix deposition to a steady state level (nonlinear fibrosis). ${ }^{17}$ Besides causing fibrosis, TAA, but not $\mathrm{CCl}_{4}$, has hepato- and cholangiocellular carcinogenic properties. In rats, biliary dysplasia and cholangiocelIular carcinoma may be observed quickly, depending on animal strain and dose-dependent toxicity on the biliary tract. ${ }^{20} \mathrm{HCC}$ development is slower as hepatocellular cancers appear on a background of chronic liver fibrosis after several months of TAA administration, ${ }^{21}$ recapitulating the multistage process of human carcinogenesis. Other hepatotoxins, such as DEN and DMN, are also used to induce HCC in the context of chronic fibrosis. ${ }^{22-24}$ 


\section{Animal models of biliary fibrosis}

Cholestatic liver disease encompasses a large variety of entities that may lead to biliary fibrosis, cirrhosis, and endstage liver disease independently of etiology. Several animal models are available and attempt to reproduce cholestatic liver injuries and related fibrosis in a specific context according to the human pathology.

CBDL is the archetype model for obstructive cholestasis, since the interruption of bile flow induces an intense ductular proliferative response, portal inflammation, and rapid establishment of portal fibrosis. ${ }^{25,26}$ The structural and functional changes due to CBDL have been extensively reported in the literature. ${ }^{27}$ The main controversy involves the severity of induced fibrosis and the celerity of severe fibrosis development. Some works describe liver cirrhosis 15-28 days after $\mathrm{CBDL}^{28,29}$ while others are unable to demonstrate evidence of cirrhosis after 40 days. ${ }^{30-32}$ Interestingly, the study of fibrosis reversibility is feasible in this model by using bilioduodenal anastomosis or choledoco-jejunostomy surgical techniques to restore normal biliary outflow. ${ }^{33,34}$ The occurrence of surgical complications (e.g. bile leakage and subsequent sepsis) is the main pitfall of the CBDL model. This may occur more frequently in mice than rats because of the more pronounced fragility of some mouse strains, especially transgenic mice, and the inevitable dilatation of the gall bladder (not present in rat) and subsequent perforation and bilioperitoneum. ${ }^{35}$

PSC is a chronic cholestatic liver disease characterized by strictures of the biliary tree due to an inflammatory and fibrotic process affecting the intra- and extra-hepatic bile ducts. Main complications are irregular bile duct obstruction, development of secondary biliary cirrhosis, and cholangiocarcinoma. ${ }^{36}$ Pathogenesis of PSC is incompletely understood, but this entity has been described as an immune-mediated phenomenon triggered by environmental factors in genetically susceptible individuals. ${ }^{37}$ The perfect animal model that summarizes all the attributes of PSC (cholangitis of the intra- and extra-hepatic bile ducts in association with gut inflammation and development of cholangiocarcinoma and/or secondary biliary cirrhosis) and exhibits a male predominance does not exist. However, several animal models may be used to study individual features. ${ }^{38}$ From a fibrosis point of view, the most relevant one is the $A b c b 4-/-$ mouse model. Mice deficient in the phospholipid transporter multi-drug resistant protein 2 (MDR2), encoded by the $A b c b 4$ gene, rapidly develop after birth inflammatory cholangitis with portal inflammation and ductular proliferation, onionskin-type periductal fibrosis, focal obliteration of the bile ducts, extra- and intrahepatic biliary strictures, and segmental duct dilation. ${ }^{39}$ The near total absence of phospholipid secretion into bile in $A b c b 4-/-$ mice results in increased concentration of free non micellar bile acids, which have toxic effects on the apical membrane of hepatocytes and cholangiocytes. ${ }^{40}$ This animal model can also be used as a model for the human hepatic disease due to MDR3 (the human orthologue of MDR2) deficiency. In humans, this genetic defect may lead to a wide spectrum of clinical phenotypes, ranging from neonatal cholestasis to biliary cirrhosis of adulthood. ${ }^{41}$

Primary biliary cirrhosis (PBC) is a liver-specific autoimmune disease mostly affecting middle-aged women and is characterized by the presence of anti-mitochondrial antibodies and progressive destruction of the small bile ducts, causing liver fibrosis, portal hypertension, and potentially liver failure. ${ }^{36,42}$ Similar to PSC, the interplay between genetic predisposition and environmental factors is a major contributor to pathogenesis of PBC and explains why it is difficult to define relevant animal models that mimic disease pathophysiology. PBC models include inducible and genetically modified animals and represent good tools to investigate the genetics and immunoregulation occurring in the earliest stage of the disease. ${ }^{43,44}$ There are only two models in the literature that eventually lead to fibrosis: (i) C57BL/ 6 mice co-immunized with 2-octynoic acid coupled to bovine serum albumin and $\alpha$-galactosylceramide (2OA-BSA- $\alpha$-GalCer mice), an invariant natural killer $\mathrm{T}$ cell activator, develop fibrous septa 4 weeks postimmunization; ${ }^{45}$ (ii) $A e 2_{a, b}{ }^{-1-}$ mice have a widespread disruption of the $\mathrm{Cl}^{-} / \mathrm{HCO}_{3}{ }^{-}$anion exchanger 2 (AE2) and develop elderly immunologic and hepatobiliary changes similar to PBC with slight liver fibrosis. ${ }^{46}$ Increased levels of anti-mitochondrial antibodies are found in both of these models. ${ }^{45,46}$

Some modified diets can induce biliary damages. A diet containing 3,5-diethylcarbonyl-1,4-dihydrocollidine (DDC), a porphyrinogenic hepatotoxin, causes the formation of porphyrin crystals within the hepatocytes in the periportal region and porphyrin plugs in small bile ducts. The tissue response involves a florid ductular reaction, peri-cholangitis, periductal fibrosis, and portal-portal fibrosis after 4-8 weeks that resembles sclerosing cholangitis in humans. ${ }^{47} \alpha$-naphtylisothiocyanate (ANIT) is a hepatocyte and bile duct epithelial cell toxicant. When conjugated to glutathione in hepatocytes, ANIT is secreted by the MRP2 transporter into bile, where it can exert its toxic effect on biliary cells. As the ANITglutathione complex is not stable in the bile, free ANIT undergoes recycling rounds of absorption and metabolism, leading to a high and toxic biliary concentration. ${ }^{48,49}$ Animals exposed chronically to low doses of ANIT develop periportal inflammation, mild hepatocellular injury, significant bile duct proliferation, and progressive fibrosis. ${ }^{50,51}$

\section{Autoimmune fibrosis}

AIH consists of a progressive T cell-mediated necroinflammatory and fibrotic process in the liver, likely triggered by the combination of environmental factors, failure of immune tolerance, and genetic predisposition. ${ }^{52}$ Considering the animal models, the difficulty lies in the breakage of immune tolerance and the long-term maintenance of immune alterations necessary for progression to chronic hepatitis and liver fibrosis. Several animal models have been proposed, ${ }^{53,54}$ but very few reproduce chronic hepatitis and develop fibrosis. The double transgenic mouse Alb-HA/CL4-TCR spontaneously develops histologic features of $\mathrm{AIH}$ and hepatic fibrosis, exclusively in males. This mouse expresses the influenza virus hemagglutinin autoantigen (HA) under the control of mouse albumin regulatory elements and $\alpha$-fetoprotein enhancer (Alb) (Alb-HA mouse), and a specific T-cell receptor (TCR) (CL4-TCR mouse). ${ }^{55}$ Wild-type FVB/N mice infected with adenovirus Ad5 expressing human cytochrome P450 2D6 (Ad-2D6) develop a chronic and severe form of AIH with extensive fibrosis and generate type 1 liver kidney microsomal-like antibodies similar to type 2 AIH patients. ${ }^{56}$

Schistosoma infection and prolonged administration of heterologous serum, mainly porcine serum, are other ways to study hepatic fibrosis development triggered by an initial immunologic stimulus. ${ }^{57-60}$ 
Delire B. et al: Animal models of liver fibrosis

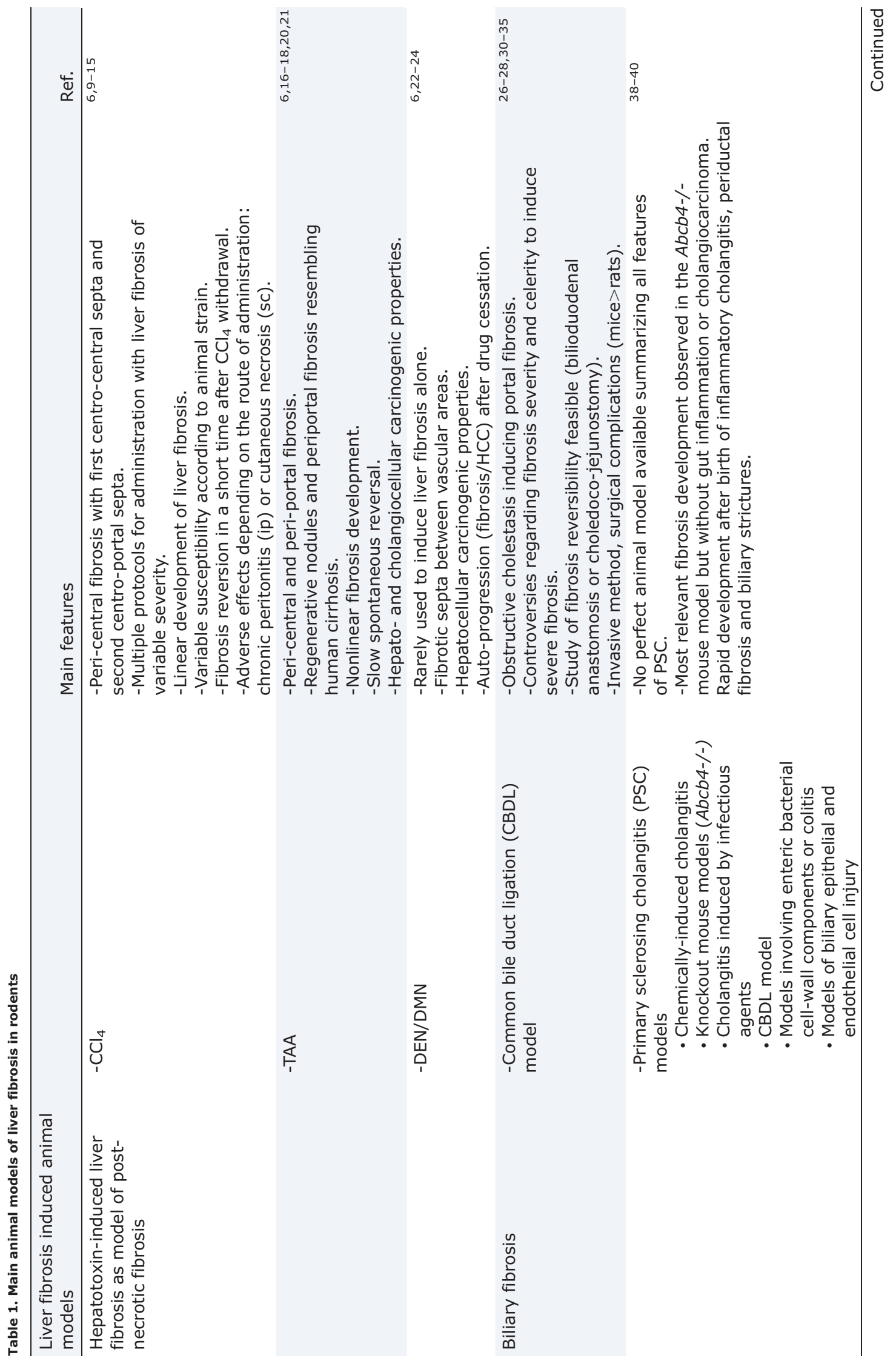


Delire B. et al: Animal models of liver fibrosis

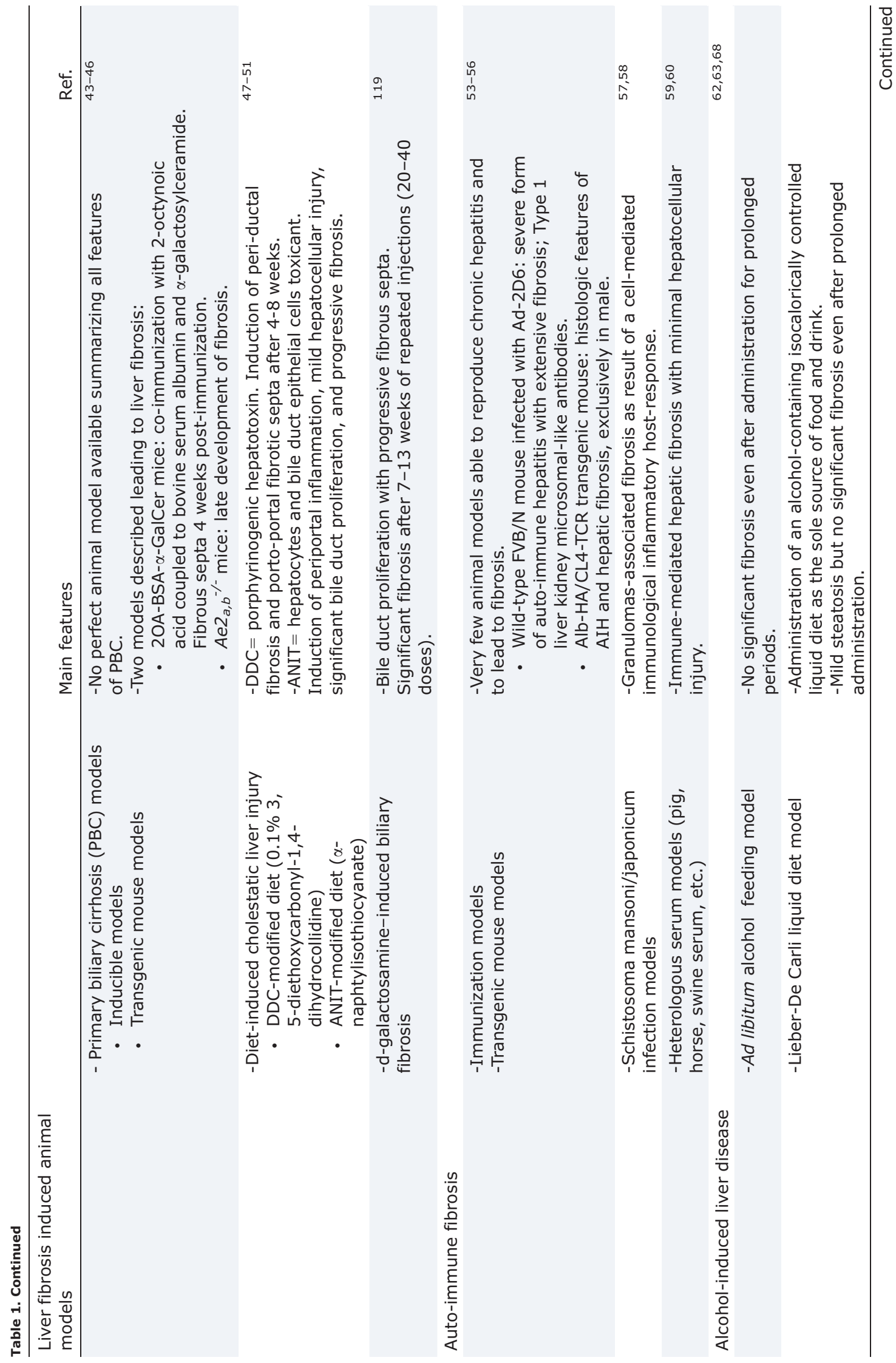


Delire B. et al: Animal models of liver fibrosis

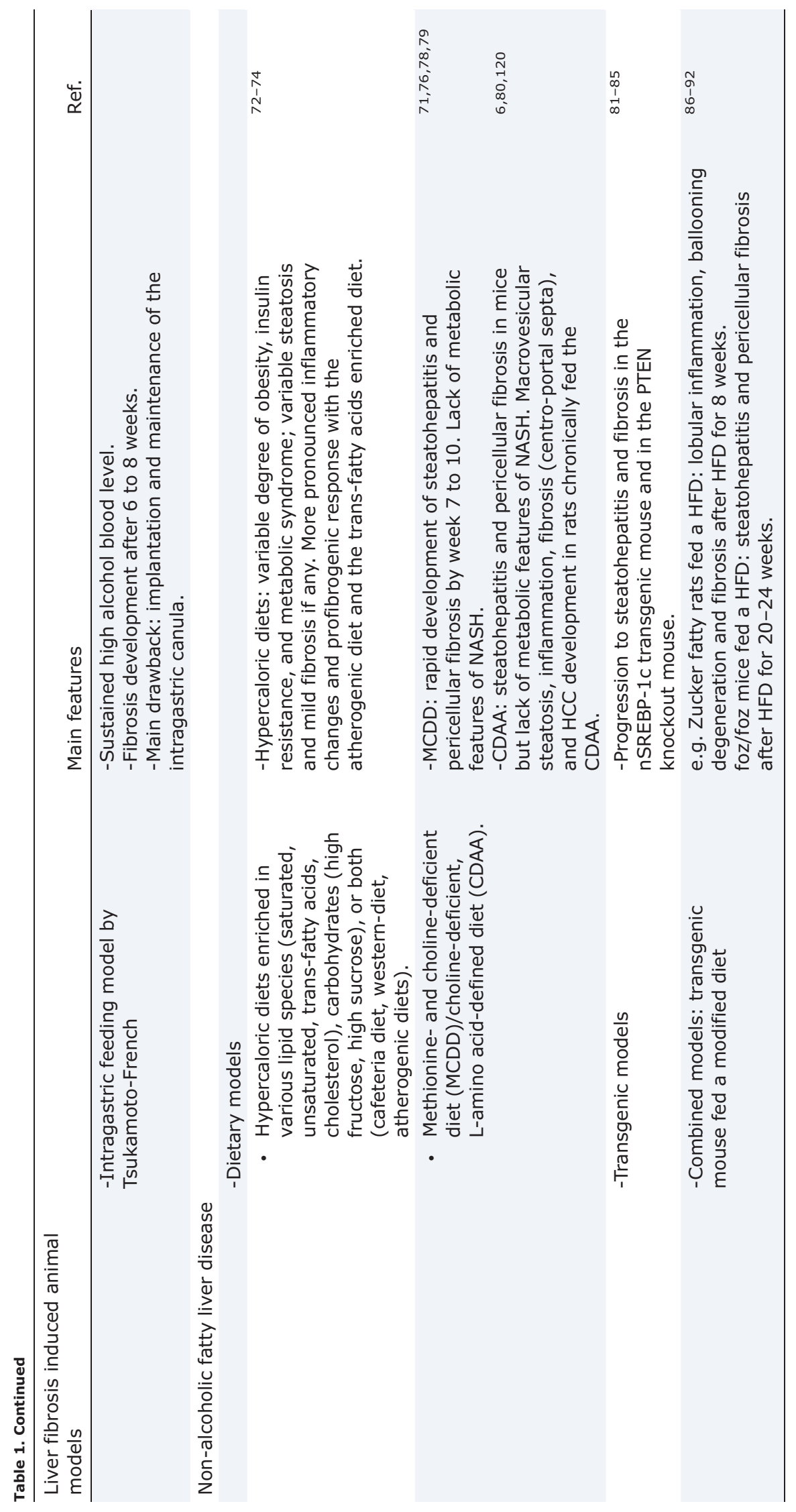


Delire B. et al: Animal models of liver fibrosis

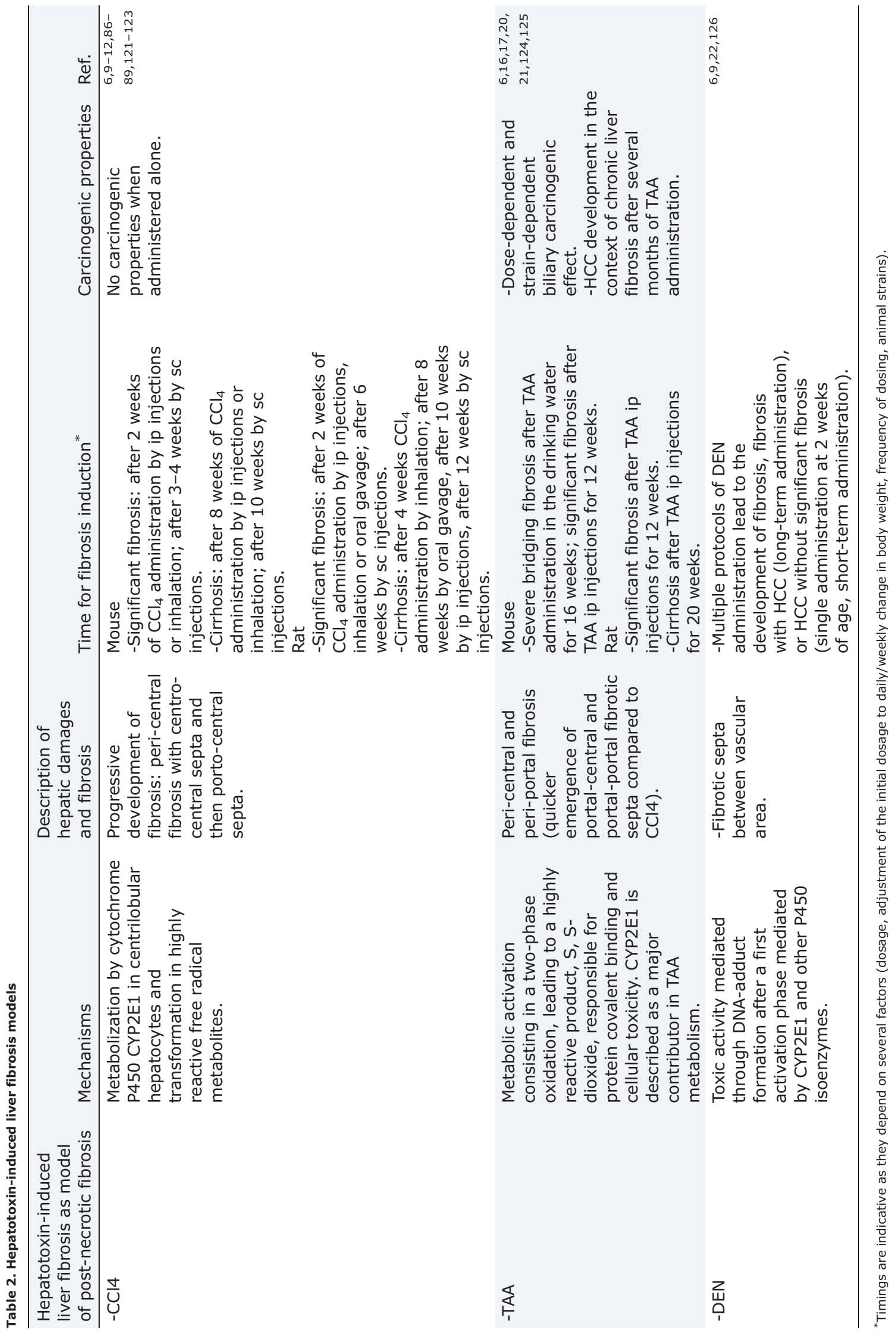




\section{Alcohol-induced fibrosis}

ALD is a major public health burden, representing the first cause of advanced liver disease in Europe. Chronic consumption of alcohol may lead to progressive hepatic impairment, ranging from simple steatosis to alcoholic steatohepatitis (ASH), progressive fibrosis, cirrhosis, and HCC. ${ }^{61}$ ALD pathogenesis is complex and includes changes in hepatic metabolism that lead to accumulation of lipids, depletion of essential nutrients, and enhanced hepatotoxicity. Persistent hepatic damage and sustained inflammation are associated with formation of reactive oxygen species (ROS), induction of an inflammatory immune response, HSCs activation, and collagen deposition. This complexity is enhanced when considering other factors like alcohol-induced changes in the gut microbiome, inter-individual susceptibility, and the large panel of alcohol consumption behaviors. To date, despite major efforts, no animal model has been able to recapitulate all features of alcoholic disease. ${ }^{62,63}$ Moreover, natural aversion to alcohol, absence of an addictive behavior, spontaneous reduction in alcohol intake when acetaldehyde blood levels increase, a high rate of alcohol catabolism, and a high basal metabolic rate impair the ability to obtain and maintain over time high blood alcohol levels in rodents and explain the paucity of hepatic damage. ${ }^{63}$

Several animal models for ALD have been developed and have been reviewed elsewhere. ${ }^{62}$ Briefly, the Lieber-De Carli model, the oldest model of chronic alcohol consumption, consists of administering an alcohol-containing isocalorically controlled liquid diet (with up to $36 \%$ calories from alcohol) as the sole source of food and drink. ${ }^{64}$ It induces mild steatosis and low-grade inflammation but not significant fibrosis, even after prolonged administration. ${ }^{63,65}$ This animal model is considered appropriate to study the early stages of ALD but not the mechanisms implicated in alcohol induced-fibrosis. Similar histological changes are observed after alcohol administration ad libitum in the drinking water. ${ }^{66}$

The intragastric feeding model was developed by Tsukamoto and French to overcome the natural aversion of animals to alcohol and to achieve a sustained high blood alcohol level. ${ }^{67}$ Rats fed according to this method develop steatosis, inflammation, and peri-central necrosis in about 2 to 4 weeks and fibrosis after 6 to 8 weeks. ${ }^{8}$ The implantation and maintenance of the intragastric cannula are the major technical limitations of this model. ${ }^{68}$

\section{Models of NASH-associated fibrosis}

Obesity, dyslipidemia, type 2 diabetes, and metabolic syndrome are major risk factors associated with non-alcoholic fatty liver disease (NAFLD). NAFLD covers a large spectrum of histological changes, including nonalcoholic fatty liver (NAFLdefined as the presence of hepatic steatosis with no evidence of hepatocellular injury), NASH (defined as the presence of steatosis, lobular or portal inflammation, and hepatocyte injury (ballooning)), pericellular fibrosis, cirrhosis, and HCC. ${ }^{69}$

The ideal animal model that recapitulates all aspects of the pathogenesis of human NAFLD, the typical histological features and progression, and the metabolic background (obesity, insulin resistance, hyperglycemia, hyperinsulinemia, dyslipidemia, altered adipokine profiles) does not exist. However, several models are described and may be classified in (i) dietary, (ii) genetic, and (iii) combined models. ${ }^{6}$ Steatosis is a common feature of these models; in some, steatohepatitis does occur but progression to liver fibrosis is uncommon. ${ }^{70}$ Obesity and metabolic syndrome are not systematically reproduced. ${ }^{6}$

Animals fed a large variety of modified diets have been described. The diets are hypercaloric, enriched in various lipid species (saturated, unsaturated, trans-fatty acids, cholesterol), carbohydrates (high fructose, high sucrose), or both (cafeteria diet, western-diet, atherogenic diets). ${ }^{70,71}$ Such dietary manipulations are usually associated with varying degrees of obesity, insulin resistance, and metabolic syndrome. Steatosis may or not be seen, sustained inflammation is uncommon, and fibrosis, if any, inconspicuous. The more pronounced phenotype is observed using atherogenic diets or trans-fat enriched diets. An atherogenic diet containing cholesterol and choline induces progressive steatosis, steatohepatitis, and pericellular fibrosis in a time-dependent manner both in rats and mice. ${ }^{72,73}$ Interestingly, mice fed this atherogenic diet remain remarkably insulin sensitive, reflecting a different metabolic status compared to the human NASH situation. ${ }^{73}$ Trans-fatty acids are the result of the industrial hardening of the vegetable oils and are found in fast-foods. They are thought to play a major role in the development of a severe phenotype with necroinflammatory changes and profibrogenic responses in a NAFLD model in mice fed ad libitum high-fat chow containing trans-fats. ${ }^{74}$

The methionine- and choline-deficient diet (MCDD) is deficient in two essential factors for the formation of phosphatidylcholine, which is involved in very low density lipoprotein (VLDL) production and secretion from the liver. ${ }^{75}$ Steatohepatitis occurs rapidly after starting the MCDD, and perisinusoidal fibrosis is observed by week 7 to $10 .{ }^{76}$ The severity of MCDD-induced histological changes in rodents depends on species, strain and gender of the animals. ${ }^{71,77}$ The MCDD is one of the most commonly used animal models of $\mathrm{NASH}$, as it induces a liver pathology that recapitulates the sequence and progression of liver pathology seen in humans. However, MCDD induces hypercatabolism, significant weight loss, and hypersensitivity to insulin. ${ }^{78,79}$ This specific metabolic profile has to be taken into account when drawing conclusions using this model.

The choline-deficient, L-amino acid-defined diet (CDAA) is a variant of the MCDD as it contains a low amount of methionine. Although it acts via a similar mechanism as the $M C D D$, the CDAA diet, in contrast, induces moderate pericellular fibrosis in mice. In rats, CDAA results in homogenous severe macrovesicular steatosis and unspecific inflammation. After a long time, fibrosis evolves rapidly, forming centroportal bridges. HCC develops with a high incidence in rats chronically fed the CDAA. ${ }^{6,80}$

The large variety of genetic models available for NAFLD have been reviewed elsewhere. ${ }^{81}$ Among those, only two spontaneously progress to steatohepatitis and fibrosis: nuclear sterol regulatory element-binding protein $1 \mathrm{c}$ (nSREBP-1c) transgenic mice and the PTEN knockout mice. nSREBP-1c transgenic mice overexpress nSREBP-1c in adipose tissue under the control of the adipocyte-specific aP2 enhancer/promoter. These mice are characterized by a disordered differentiation of adipose tissue, marked insulin resistance, diabetes mellitus, fatty liver with inflammatory cell infiltration, and pericellular fibrosis in mice aged 20 weeks or more. ${ }^{82,83}$ PTEN is a tumor suppressor gene and a negative regulator of several signaling pathways implicated in insulin signaling, apoptosis, cell proliferation, and tumor formation. ${ }^{84} \mathrm{~A}$ hepatocyte-specific null mutation of PTEN 
may be generated in mice with the Cre-loxP system (AlbCrePtenflox/flox mice). Steatosis develops at 10 weeks of age, and steatohepatitis and fibrosis are present at 40 weeks of age. Moreover, two-thirds of the animals have HCC by 74-78 weeks of age. ${ }^{85}$

As NAFLD transgenic models rarely progress to severe stages of disease, a "second hit" is often necessary, such as the MCDD or a high fat diet (HFD), to favor NASH and fibrosis development. ${ }^{86}$ The low-density lipoprotein receptor deficiency mouse (LDLR-/-) is a widely-used hypercholesterolemic atherosclerosis model. When fed a HFD, middle-aged $L D L R-/-$ mice develop NASH associated with metabolic syndrome. In this model, aging and the LDLR deficiency status contribute to the development of a NASH severe phenotype. Middle-aged $L D L R-/-$ mice develop steatosis, inflammation, and fibrosis; while young $L D L R-/-$ mice and middle-age wild type mice are protected from inflammation and hepatocellular injury. ${ }^{87}$ Fatty Zucker rats ( $\mathrm{fa} / \mathrm{fa}$ rats) have a natural mutation in the leptin receptor and exhibit severe obesity, insulin resistance, and hyperphagia. They have a fatty liver without signs of progression to NASH. ${ }^{88,89}$ Administration of an HFD for 8 weeks induces lobular inflammation, ballooning degeneration, and fibrosis. ${ }^{90}$ Another attractive "second hit" model is foz/foz mice fed a HFD. These mice have a mutation in the Alms1 gene that encodes a ciliary protein that interferes with the central control of satiety. ${ }^{91}$ Foz/foz mice spontaneously develop obesity, severe insulin resistance, and diabetes, whereas foz/foz mice fed a HFD progress from steatosis to steatohepatitis and pericellular fibrosis after 20-24 weeks. ${ }^{92}$ "Second hit strategies" have been also reported using other genetically modified or selected animals with disorders in lipid/glucose homeostasis, including Abc11-/-, ppara-/-, db/db, ApoE-/-mice, and Otsuka LongEvans Tokushima Fatty (OLETF) rats. ${ }^{6}$

\section{Genetically modified models, cell tracking, and cell targeting}

\section{Gene overexpression or silencing}

Targeted gene disruption or overexpression in rodents allows for the study of multiple factors associated with hepatic fibrosis and implicated in different signaling cascades related, for instance, to hepatocyte necrosis/apoptosis, growth factordependent fibrosis, immune response, and inflammatory cytokines. Constitutive, inducible, and/or cell specific gene manipulations are often used in combination with precited models to examine the impact of a specific pathway on the fibrotic process. ${ }^{93-95}$ Some of these models disrupt key fibrogenic components or alter hepatocyte function and spontaneously cause liver fibrosis. These include: transgenic mice overexpressing transforming growth factor beta1 (TGF$\beta 1$ ) that spontaneously develop liver fibrosis; ${ }^{96}$ liver-specific and inducible overexpression of platelet-derived growth factor-beta (PDGF- $\beta$ ) that induce HSCs activation and liver fibrosis $;{ }^{95}$ MDR2 deficiency that causes biliary fibrosis; ${ }^{39}$ and hepatospecific c-myc overexpression that is associated with HSC activation. ${ }^{97}$ Accordingly, these transgenic mice may be used as disease models.

\section{Single cell gene expression modulation, fate tracing, and targeting: the example of hepatic stellate cells}

HSCs are key effector cells in hepatic fibrosis, and the understanding of HSC biology is crucial for the identification of novel targets for antifibrotic therapy. In the last two decades, the isolation and culture of primary HSCs, that in some respects recapitulates the activation process undergone during in vivo fibrogenesis, have been and remain a fantastic tool to study features of HSCs. This reductionist model, however, is artificial and not sufficient to evaluate all aspects of HSC biology. Gene expression patterns of HSCs isolated from animals with CBLD or $\mathrm{CCl}_{4}$-induced liver fibrosis (in vivo activated) are significantly different from changes in genes expression during culture-activation of primary HSCs (in vitro activated). ${ }^{98,99}$ Similarly, HSCs isolated from normal human liver and activated in culture express genes related to fibrogenesis and contractility while activated HSCs isolated from cirrhotic patients have a different gene expression profile related to ECM, inflammation and apoptosis. ${ }^{100}$ The different phenotype of HSCs, whether they are activated in vivo or in vitro, suggests an important role of cell-cell and cell-ECM interactions in the control of HSC biology. Taken together, these findings demonstrate the need to develop and use tools able to experimentally target and manipulate HSCs in vivo.

Stellate cell specific gene silencing can be obtained using the Cre recombinase system under the control of the glial fibrillary acid protein (GFAP) promoter (GFAP-Cre) that is activated in resting HSCs. Using this approach, the role of autophagy in HSCs during fibrogenesis has been demonstrated. Deletion of the autophagy-related protein 7 (ATG7) mediated by the Cre recombinase under the control of the GFAP promoter reduces matrix deposition and liver fibrosis following $\mathrm{CCl}_{4}$ or TAA injury. ${ }^{101}$ GFAP-dependent gene overexpression or silencing in HSCs may also be combined with the tetracycline-responsive system (TRE) to reversibly control gene expression. ${ }^{102}$ In many cell types, including HSCs, tumor suppressor p53 participates in senescence. Inducible p53 specific silencing in HSCs can be generated by crossing mice harboring a TRE driven short hairpin RNA (shRNA) capable of efficiently suppressing $p 53$ expression with mice harboring a tetracycline-controlled transactivator (tTA) transgene expressed from the GFAP promoter. In the absence of tetracycline, tTA is expressed in HSCs, binds the TRE promoter, and drives shRNA transcription that suppresses p53 expression. ${ }^{103}$ Interestingly, this specific suppression of p53 in HSCs leads to an increase in activated HSCs, ECM deposition, and fibrosis after $\mathrm{CCl}_{4}$ exposition, suggesting a role for senescence in HSCs in limiting fibrosis reaction. ${ }^{103}$ Deletion in HSCs may be reached in mice expressing the herpes simplex virus-thymidine kinase (HSV-Tk) gene driven by the GFAP promoter. In response to ganciclovir, only the proliferating HSCs are affected and depleted, allowing for the study of activated HSCs depletion on liver injury and repair. Using this system in the $\mathrm{CCl}_{4}$ and in the CBDL model, not only was the expression of HSC activation markers decreased but liver fibrosis was significantly reduced. ${ }^{104}$ Caution should be taken regarding these results, as GFAP expression has recently been localized in cholangiocytes as well. ${ }^{105}$

For several years, the nature and fate of matrix-producing cells during fibrosis induction, maintenance, and resolution has been a question of great interest. HSCs and portal fibroblasts are considered the major contributors of ECM production in the fibrotic process since they may activate into myofibroblast-like cells during chronic liver injury. Experiments using bone marrow transplantation, chimeric mice, and genetic labeling of epithelial liver cells confirmed negligible, if any, participation of extrahepatic cells or liver 
epithelial cells in the production of matrix in the fibrotic liver. ${ }^{106-108}$ Recently, Schwabe's team developed a new transgenic mouse model to perform fate mapping in HSCs and demonstrated that HSCs are the major contributor of the myofibroblast pool in $\mathrm{CCl}_{4}$-induced liver fibrosis. ${ }^{105}$ Mice expressing the Cre recombinase under the lecithin-retinol acyltransferase (Lrat) promoter were crossed with mice expressing ZsGreen Cre reporter. As Lrat expression is restricted to HSCs and undetectable in other liver cell types, including portal myofibroblasts, the system allow for specific tagging of $99 \%$ of $\mathrm{HSCs}^{105}$ In $\mathrm{CCl}_{4}$-induced liver fibrosis, cells expressing fluorescent ZsGreen have an overlap of more than $90 \%$ with alpha-smooth muscle actin ( $\alpha$ SMA) expressing cells, providing further evidence that HSCs are the major contributor to the myofibroblast pool. Moreover, in mice coexpressing the red-fluorescent LratCre reporter tdTomato and a green-fluorescent collagen-GFP reporter, there was a strong overlap between red and green cells, demonstrating that HSCs are a major cell source of collagen in the fibrotic liver. These results are confirmed in the TAA-induced liver fibrosis model and models of cholestatic fibrosis, such as $\mathrm{CBDL}$, DDC-containing diet, and $M d r 2^{-/-}$mouse models. In these cholestatic models, $\alpha$ SMA- and collagen-GFP positive but LratCre Tomato negative cells were described around the portal tracts and considered to be portal fibroblasts, while the population of $>89 \%$ positive matrix producing activated HSCs expanded in fibrotic areas. ${ }^{105}$ Such experiments confirm that portal myofibroblasts and activated HSCs are two distinct cell populations, with different origins and contributions to fibrogenesis.

Genetic cell tracing tools have also been used to elucidate the fate of activated HSCs/myofibroblasts during fibrosis resolution. ${ }^{19}$ In Col- $\alpha 2$ (I) ${ }^{\text {Cre-YFP }}$ mice and Col- $\alpha 1(1)^{\text {Cre-YFP }}$ mice, induction of collagen expression in HSCs and myofibroblasts during fibrogenesis drives the expression of yellow fluorescent protein (YFP). The latter will remain during the entire life of the cell. Upon $\mathrm{CCl}_{4}$-induced fibrogenesis, $\alpha$-SMA positive activated HSCs and myofibroblasts coexpress YFP. After cessation of $\mathrm{CCl}_{4}$ administration, $\alpha$-SMA positive cells gradually decrease in number and are undetectable 1 month after the last $\mathrm{CCl}_{4}$ dose, while YFP positive cells persist in liver parenchyma. This provides strong experimental evidence that a pool of previously activated HSCs reverts to an inactive phenotype during fibrosis regression. ${ }^{109}$ In collagen-GFP mice characterized by a collagen-driven GFP expression, activated HSCs undergo apoptosis in the earliest stage of fibrosis resolution, as colocalization of caspase- 3 and GFP are observed in the liver of mice 7 days after $\mathrm{CCl}_{4}$ cessation. ${ }^{109}$ Collagen-I degradation seems to be critical during spontaneous fibrosis recovery, since a mutation in collagen-I that confers resistance to collagenase leads to persistent HSCs activation and reduced HSCs apoptosis. ${ }^{110}$

Such transgenic models or other systems for genome edition such as the clustered regularly interspaced short palindromic repeats (CRISPR)/Cas system ${ }^{111}$ will undoubtedly be used more commonly for time- and cell-type specific control of gene expression or silencing. Use of these techniques will provide deeper insight into decisive signaling pathways implicated in HSC-dependent fibrogenesis and help to identify targets for therapeutic purposes.

Drug delivery systems are designed to specifically target compounds to specific cell types. As reviewed elsewhere, several systems are available for targeting hepatocytes, Kupffer cells, sinusoidal endothelial cells, cholangiocytes, and stellate cells. ${ }^{112}$ Vitamin A-coupled liposomes are being developed for HSC targeting. The strategy is based on the ability of HSCs to store retinol, a function shared with no other hepatic cell. Small interfering RNA (siRNA), gene vectors or drugs may be encapsulated in liposomes for specific delivery to HSCs. ${ }^{113,114}$ In vitro testing confirm that Vitamin A-coupled liposomes could deliver a potential antifibrotic compound into HSCs and reduce the level of fibrotic factors in vitro, whereas most of the liposomes localize to the liver with very little spread to other organs after in vivo administration. ${ }^{113,114}$ Albumin-based carriers that bind to receptors highly expressed on activated HSCs (such as the mannose 6-phosphate/insulin-like growth factor II receptor, the collagen type VI receptor, and the platelet-derived growth factor beta (PDGF- $\beta$ ) receptor $)^{112}$ or coupled to single cyclic peptide ${ }^{115}$ have been designed to deliver drugs to HSCs with high efficiency.

\section{Mice with humanized livers}

Mice fail to reproduce the whole spectrum of pathological aspects observed in humans liver diseases. To overcome this problem, major efforts are devoted to generate mice with humanized livers. To do this, the murine hepatocyte population of immunodeficient mice (to avoid graft rejection) is replaced with human hepatocytes via transplantation, following constitutive or inducible hepatic injury. Four transgenic models are described: the albumin-uroplasminogen activator (uPA) transgenic mouse, the fumarylacetoacetate hydrolase (Fah) gene knockout mouse, the TK-NOG transgenic mouse, and the AFC 8 transgenic mouse. ${ }^{116}$ In all systems, the repopulated liver shows normal hepatocyte function and morphology and respects a normal hepatic architecture with typical zonation. A high (>70\%) rate of hepatocyte repopulation is reached in the uPA transgenic mouse, the Fah gene KO mouse, and the TK-NOG mouse ${ }^{116}$ but not in the AFC 8 transgenic mouse $(15-25 \%) .{ }^{117}$ In the AFC 8 transgenic mouse, not only is the liver repopulated by human hepatocytes but a functional human immune system is also reconstituted after the injection of $\mathrm{CD} 34+$ human hematopoietic stem cells. ${ }^{117}$

Several applications for mice with humanized livers have been described: infectious diseases, liver gene therapy, stem cell biology, drug metabolism, and modeling of human genetic disease. ${ }^{116}$ The first aim of human-murine chimeric liver mouse model development was establishment of a permissive liver to viral infection. Although hepatitis $B$ (HBV) and $\mathrm{C}(\mathrm{HCV})$ viruses infect and replicate in human hepatocytes, they do not infect rodents, since their hepatocytes do not support virus entry and replication. Several years ago, transgenic mouse models were developed that express the whole genome or individual genes of HBV or HCV. As the mouse immune system tolerates the transgenetically expressed viral proteins, infection develops without liver inflammation and without liver fibrosis. ${ }^{117}$ The humanized uPA, the Fah-/-, and the TK-NOG transgenic mice support $\mathrm{HBV} / \mathrm{HCV}$ infection and replication. Unfortunately, as they lack a functional human immune system, they do not allow for the study of the host immune response. The AFC8 and A2/ NSG/Fas humanized mouse models have both human liver and human immune cells, and these models support HCV and HBV liver infection, respectively, leading to viral hepatitis and liver fibrosis. ${ }^{117,118}$ These animal models provide an attractive opportunity to study virus induced liver fibrosis. 
The humanized mouse models are only recently available and are currently being optimized. In addition to the study of hepatotropic viruses, the next challenge will consist of evaluating these humanized mice in several well-described liver disease models, e.g. hepatotoxin fibrosis, NALD, and ALD models. The combination of human hepatocellular metabolism and human immune repertoire will likely provide a relevant system for the study of liver damage and wound healing response in liver diseases. The results of these developments are eagerly awaited. Only the future will tell whether these new models will be instrumental in generating new information regarding disease mechanisms in humans and variation in susceptibility between animals and humans. However, immune-deficiency, immune mismatch or mosaicism, the lack of other human hepatic cell types like HSCs, the variable rate of human hepatocyte engraftment, and the inevitable interactions between the humanized liver and the non-humanized extrahepatic environment might be major limitations of such approaches.

\section{Conclusions}

The human liver is a complex organ with cell-cell and cellmatrix interactions and extrahepatic crosstalk. This complexity likely underlies the difficulty in developing animal models able to recapitulate liver diseases as global entities with relevant metabolic and immunologic backgrounds and specific hepatic features. Although the classical animal models have yielded major progress in the understanding of fibrogenesis, they are not sufficient to investigate all components implicated in the pathogenesis of human liver diseases. Today, the generation of tools that allow for the study of particular pathways, soluble factors, and cellular effectors by using either cell- and time-specific genome edition or cellular targeting is of major interest. In addition, the humanized liver mouse model represents a promising perspective, particularly when used in combination with a functional human immune system. Indeed, utilizing such experimental manipulations will likely allow for a greater understanding of human liver fibrosis pathogenesis and the identification of specific novel targets for effective antifibrotic therapies.

\section{Conflict of interest}

None

\section{Author contributions}

Writing the paper (BD, PS, IL).

\section{References}

[1] Lee UE, Friedman SL. Mechanisms of hepatic fibrogenesis. Best Pract Res Clin Gastroenterol 2011;25:195-206. doi: 10.1016/j.bpg.2011.02.005.

[2] Schuppan D, Afdhal NH. Liver cirrhosis. Lancet 2008;371:838-851. doi: 10.1016/S0140-6736(08)60383-9.

[3] Popov Y, Schuppan D. Targeting liver fibrosis: strategies for development and validation of antifibrotic therapies. Hepatology 2009;50:1294-1306. doi: $10.1002 /$ hep. 23123 .

[4] Tsukamoto $H$, Matsuoka M, French SW. Experimental models of hepatic fibrosis: a review. Semin Liver Dis 1990;10:56-65. doi: 10.1055/s-20081040457.

[5] Hooijmans CR, Leenaars M, Ritskes-Hoitinga M. A gold standard publication checklist to improve the quality of animal studies, to fully integrate the
Three Rs, and to make systematic reviews more feasible. Altern Lab Anim 2010;38:167-182.

[6] Starkel P, Leclercq IA. Animal models for the study of hepatic fibrosis. Best Pract Res Clin Gastroenterol 2011;25:319-333. doi: 10.1016 /j.bpg.2011.02.004.

[7] Mailly L, Robinet E, Meuleman P, Baumert TF, Zeisel MB. Hepatitis C virus infection and related liver disease: the quest for the best animal model. Front Microbiol 2013;4:213. doi: 10.3389/fmicb.2013.00212.

[8] Iimuro Y, Ikejima K, Rose ML, Bradford BU, Thurman RG. Nimodipine, a dihydropyridine-type calcium channel blocker, prevents alcoholic hepatitis caused by chronic intragastric ethanol exposure in the rat. Hepatology 1996;24:391-397. doi: 10.1002/hep.510240217.

[9] Liedtke C, Luedde T, Sauerbruch T, Scholten D, Streetz K, Tacke F, et al. Experimental liver fibrosis research: update on animal models, legal issues and translational aspects. Fibrogenesis Tissue Repair 2013;6:19. doi: 10.1186/1755-1536-6-19.

[10] Constandinou C, Henderson N, Iredale JP. Modeling liver fibrosis in rodents. Methods Mol Med 2005;117:237-250.

[11] Regimbeau JM, Fuks D, Kohneh-Shahri N, Terris B, Soubrane O. Restrictive model of compensated carbon tetrachloride-induced cirrhosis in rats. World J Gastroenterol. 2008;14:6943-6947. doi: 10.3748/wjg.14.6943.

[12] Nagano K, Umeda Y, Saito M, Nishizawa T, Ikawa N, Arito H, et al. Thirteenweek inhalation toxicity of carbon tetrachloride in rats and mice. J Occup Health 2007;49:249-259. doi: 10.1539/joh.49.249.

[13] Shi Z, Wakil AE, Rockey DC. Strain-specific differences in mouse hepatic wound healing are mediated by divergent T helper cytokine responses. Proc Natl Acad Sci USA 1997;94:10663-10668. doi: 10.1073/pnas.94.20 .10663 .

[14] Hillebrandt S, Goos C, Matern S, Lammert F. Genome-wide analysis of hepatic fibrosis in inbred mice identifies the susceptibility locus Hfib1 on chromosome 15. Gastroenterology 2002;123:2041-2051. doi: 10.1053 /gast.2002.37069.

[15] Melhem A, Muhanna N, Bishara A, Alvarez CE, Ilan Y, Bishara T, et al. Antifibrotic activity of NK cells in experimental liver injury through killing of activated HSC. J Hepatol 2006;45:60-71. doi: 10.1016/j.jhep.2005.12. 025.

[16] Reif S, Aeed H, Shilo Y, Reich R, Kloog Y, Kweon YO, et al. Treatment of thioacetamide-induced liver cirrhosis by the Ras antagonist, farnesylthiosalicylic acid. J Hepatol 2004;41:235-241. doi: 10.1016/j.jhep.2004.04. 010.

[17] Salguero PR, Roderfeld M, Hemmann S, Rath T, Atanasova S, Tschuschner $A$, et al. Activation of hepatic stellate cells is associated with cytokine expression in thioacetamide-induced hepatic fibrosis in mice. Lab Invest 2008;88:1192-1203. doi: 10.1038/labinvest.2008.91

[18] Li X, Benjamin IS, Alexander B. Reproducible production of thioacetamideinduced macronodular cirrhosis in the rat with no mortality. J Hepatol 2002; 36:488-493. doi: 10.1016/S0168-8278(02)00011-9.

[19] Iredale JP, Benyon RC, Pickering J, McCullen M, Northrop M, Pawley S, et al. Mechanisms of spontaneous resolution of rat liver fibrosis. Hepatic stellate cell apoptosis and reduced hepatic expression of metalloproteinase inhibitors. J Clin Invest 1998;102:538-549. doi: 10.1172/JCI1018.

[20] Yeh CN, Maitra A, Lee KF, Jan YY, Chen MF. Thioacetamide-induced intestinal-type cholangiocarcinoma in rat: an animal model recapitulating the multi-stage progression of human cholangiocarcinoma. Carcinogenesis 2004;25:631-636. doi: 10.1093/carcin/bgh037.

[21] Yang JM, Han DW, Xie CM, Liang QC, Zhao YC, Ma XH. Endotoxins enhance hepatocarcinogenesis induced by oral intake of thioacetamide in rats. World J Gastroenterol 1998;4:128-132.

[22] Newell P, Villanueva A, Friedman SL, Koike K, Llovet JM. Experimental models of hepatocellular carcinoma. J Hepatol 2008;48:858-879. doi: 10.1016/j.jhep.2008.01.008

[23] George J, Rao KR, Stern R, Chandrakasan G. Dimethylnitrosamine-induced liver injury in rats: the early deposition of collagen. Toxicology $2001 ; 156$ : 129-138. doi: 10.1016/S0300-483X(00)00352-8.

[24] Vesselinovitch SD. The sex-dependent difference in the development of liver tumors in mice administered dimethylnitrosamine. Cancer Res 1969; 29:1024-1027

[25] Xu J, Liu X, Koyama Y, Wang P, Lan T, Kim IG, et al. The types of hepatic myofibroblasts contributing to liver fibrosis of different etiologies. Front Pharmacol 2014;5:167. doi: 10.3389/fphar.2014.00167.

[26] Zhang XJ, Katsuta Y, Akimoto T, Ohsuga M, Aramaki T, Takano T. Intrapulmonary vascular dilatation and nitric oxide in hypoxemic rats with chronic bile duct ligation. J Hepatol 2003;39:724-730. doi: 10.1016/S01 68-8278(03)00430-6

[27] Symeonidis A, Trams EG. Morphologic and functional changes in the livers of rats after ligation or excision of the common bile duct. Am J Pathol 1957; 33:13-27.

[28] Kountouras J, Billing BH, Scheuer PJ. Prolonged bile duct obstruction: a new experimental model for cirrhosis in the rat. Br J Exp Pathol 1984;65:305311. 
[29] Ackermann D, Mordasini D, Cheval L, Imbert-Teboul M, Vogt B, Doucet A. Sodium retention and ascites formation in a cholestatic mice model: role of aldosterone and mineralocorticoid receptor? Hepatology 2007;46:173179. doi: 10.1002/hep.21699.

[30] Johnstone JM, Lee EG. A quantitative assessment of the structural changes the rat's liver following obstruction of the common bile duct. $\mathrm{Br}]$ Exp Pathol 1976;57:85-94.

[31] Tarcin O, Basaranoglu M, Tahan V, Tahan G, Sucullu I, Yilmaz N, et al. Time course of collagen peak in bile duct-ligated rats. BMC Gastroenterol 2011; 11:45. doi: 10.1186/1471-230X-11-45.

[32] Georgiev P, Jochum W, Heinrich S, Jang JH, Nocito A, Dahm F, et al. Characterization of time-related changes after experimental bile duct ligation. Br J Surg 2008;95:646-656. doi: 10.1002/bjs.6050.

[33] Abdel-Aziz G, Lebeau G, Rescan PY, Clement B, Rissel M, Deugnier Y, et al. Reversibility of hepatic fibrosis in experimentally induced cholestasis in rat. Am J Pathol. 1990;137:1333-1342.

[34] Zimmermann H, Fellay M, Zimmermann A. Hepatic stellate cells (Ito cells) but not collagen IV may partly be responsible for lower portal pressure after reversing secondary biliary cirrhosis in the rat. J Hepatol 1997;26:158166. doi: 10.1016/S0168-8278(97)80022-0.

[35] Geerts AM, Vanheule E, Praet M, Van VH, De VM, Colle I. Comparison of three research models of portal hypertension in mice: macroscopic, histological and portal pressure evaluation. Int J Exp Pathol 2008;89: 251-263. doi: 10.1111/j.1365-2613.2008.00597.x.

[36] European Association for the Study of the Liver, Beuers U, Boberg KM, Chapman RW, Chazouillères $O$, Invernizzi P. EASL Clinical Practice Guidelines: management of cholestatic liver diseases. J Hepatol 2009;51: 237-267. doi: 10.1016/j.jhep.2009.04.009.

[37] Eaton JE, Talwalkar JA, Lazaridis KN, Gores GJ, Lindor KD. Pathogenesis of primary sclerosing cholangitis and advances in diagnosis and management. Gastroenterology 2013;145:521-536. doi: 10.1053/j.gastro.2013.06. 052.

[38] Fickert P, Pollheimer MJ, Beuers U, Lackner C, Hirschfield G, Housset C, et al. Characterization of animal models for primary sclerosing cholangitis (PSC). J Hepatol 2014;60:1290-1303. doi: 10.1016/j.jhep.2014.02.006.

[39] Mauad TH, van Nieuwkerk CM, Dingemans KP, Smit JJ, Schinkel AH, Notenboom RG, et al. Mice with homozygous disruption of the mdr2 Pglycoprotein gene. A novel animal model for studies of nonsuppurative inflammatory cholangitis and hepatocarcinogenesis. Am J Pathol 1994; 145:1237-1245.

[40] Lammert F, Wang DQ, Hillebrandt S, Geier A, Fickert P, Trauner M, et al. Spontaneous cholecysto- and hepatolithiasis in Mdr2-/- mice: a model for low phospholipid-associated cholelithiasis. Hepatology 2004;39:117-128. doi: $10.1002 /$ hep. 20022.

[41] Jacquemin E, De Vree JM, Cresteil D, Sokal EM, Sturm E, Dumont M, et al. The wide spectrum of multidrug resistance 3 deficiency: from neonatal cholestasis to cirrhosis of adulthood. Gastroenterology 2001;120:14481458. doi: 10.1053/gast.2001.23984.

[42] Leung PS, Yang GX, Dhirapong A, Tsuneyama K, Ridgway WM, Gershwin ME. Animal models of primary biliary cirrhosis: materials and methods. Methods Mol Biol 2012;900:291-316. doi: 10.1007/978-1-60761-720414.

[43] Concepcion AR, Medina JF. Approaches to the pathogenesis of primary biliary cirrhosis through animal models. Clin Res Hepatol Gastroenterol 2012;36:21-28. doi: 10.1016/j.clinre.2011.07.007.

[44] Ueno Y, Moritoki Y, Shimosegawa T, Gershwin ME. Primary biliary cirrhosis: what we know and what we want to know about human PBC and spontaneous PBC mouse models. J Gastroenterol 2007;42:189-195. doi: 10.1007/s00535-007-2019-y.

[45] Wu SJ, Yang YH, Tsuneyama K, Leung PS, Illarionov P, Gershwin ME, et al. Innate immunity and primary biliary cirrhosis: activated invariant natural killer $\mathrm{T}$ cells exacerbate murine autoimmune cholangitis and fibrosis. Hepatology 2011;53:915-925. doi: 10.1002/hep.24113.

[46] Salas JT, Banales JM, Sarvide S, Recalde S, Ferrer A, Uriarte I, et al. Ae2a,bdeficient mice develop antimitochondrial antibodies and other features resembling primary biliary cirrhosis. Gastroenterology 2008;134:14821493. doi: 10.1053/j.gastro.2008.02.020.

[47] Plum W, Tschaharganeh DF, Kroy DC, Corsten E, Erschfeld S, Dierssen U, et al. Lack of glycoprotein 130/signal transducer and activator of transcription 3-mediated signaling in hepatocytes enhances chronic liver injury and fibrosis progression in a model of sclerosing cholangitis. Am J Pathol. 2010;176:2236-2246. doi: 10.2353/ajpath.2010.090469.

[48] Jean PA, Bailie MB, Roth RA. 1-naphthylisothiocyanate-induced elevation of biliary glutathione. Biochem Pharmacol 1995;49:197-202. doi: 10.1016 10006-2952(94)00469-2.

[49] Dietrich CG, Ottenhoff R, de Waart DR, Oude Elferink RP. Role of MRP2 and GSH in intrahepatic cycling of toxins. Toxicology $2001 ; 167: 73-81$. doi: $10.1016 /$ S0300-483X(01)00459-0.
[50] Tjandra K, Sharkey KA, Swain MG. Progressive development of a Th1-type hepatic cytokine profile in rats with experimental cholangitis. Hepatology 2000;31:280-290. doi: 10.1002/hep.510310204.

[51] Sullivan BP, Weinreb $\mathrm{PH}$, Violette SM, Luyendyk JP. The coagulation system contributes to alphaVbeta6 integrin expression and liver fibrosis induced by cholestasis. Am J Pathol 2010;177:2837-2849. doi: 10.2353/ajpath.2010. 100425.

[52] Manns MP, Czaja AJ, Gorham JD, Krawitt EL, Mieli-Vergani G, Vergani D, et al. Diagnosis and management of autoimmune hepatitis. Hepatology 2010;51:2193-2213. doi: 10.1002/hep.23584.

[53] Yuksel M, Laukens D, Heindryckx F, Van VH, Geerts A, Wong FS, et al. Hepatitis mouse models: from acute-to-chronic autoimmune hepatitis. Int J Exp Pathol 2014;95:309-320. doi: 10.1111/iep.12090.

[54] Jaeckel E, Hardtke-Wolenski M, Fischer K. The benefit of animal models for autoimmune hepatitis. Best Pract Res Clin Gastroenterol 2011;25:643651. doi: $10.1016 /$ j.bpg.2011.10.006.

[55] Zierden M, Kuhnen E, Odenthal M, Dienes HP. Effects and regulation of autoreactive CD8+ T cells in a transgenic mouse model of autoimmune hepatitis. Gastroenterology 2010;139:975-986.e3. doi: 10.1053/j.gastro .2010.05.075

[56] Holdener M, Hintermann E, Bayer M, Rhode A, Rodrigo E, Hintereder G, et al. Breaking tolerance to the natural human liver autoantigen cytochrome P450 2D6 by virus infection. J Exp Med 2008;205:1409-1422. doi: 10.1084/jem.20071859.

[57] Dunn MA, Rojkind M, Warren KS, Hait PK, Rifas L, Seifter S. Liver collagen synthesis in murine schistosomiasis. J Clin Invest 1977;59:666-674. doi: 10.1172/JCI108685.

[58] Bartley PB, Ramm GA, Jones MK, Ruddell RG, Li Y, McManus DP. A contributory role for activated hepatic stellate cells in the dynamics of Schistosoma japonicum egg-induced fibrosis. Int J Parasitol 2006;36:9931001. doi: 10.1016/j.ijpara.2006.04.015.

[59] Paronetto F, Popper H. Chronic liver injury induced by immunologic reactions. Cirrhosis following immunization with heterologous sera. Am J Pathol 1966;49:1087-1101.

[60] Baba Y, Saeki K, Onodera T, Doi K. Serological and immunohistochemical studies on porcine-serum-induced hepatic fibrosis in rats. Exp Mol Pathol 2005;79:229-235. doi: 10.1016/j.yexmp.2005.08.007.

[61] European Association for the Study of Liver, Mathurin $P$, Hadengue $A$, Bataller R, Addolorato G, Burra $P$, et al. EASL clinical practical guidelines: management of alcoholic liver disease. J Hepatol 2012;57:399-420. doi: 10.1016/j.jhep.2012.04.004.

[62] Mathews S, Xu M, Wang H, Bertola A, Gao B. Animals models of gastrointestinal and liver diseases. Animal models of alcohol-induced liver disease: pathophysiology, translational relevance, and challenges. Am ] Physiol Gastrointest Liver Physiol 2014;306:G819-G823. doi: 10.1152 /ajpgi.00041.2014.

[63] Brandon-Warner E, Schrum LW, Schmidt CM, McKillop IH. Rodent models of alcoholic liver disease: of mice and men. Alcohol 2012;46:715-725. doi: 10.1016/j.alcohol.2012.08.004.

[64] Iseri OA, Lieber CS, Gottlieb LS. The ultrastructure of fatty liver induced by prolonged ethanol ingestion. Am J Pathol 1966;48:535-555.

[65] Leo MA, Lieber CS. Hepatic fibrosis after long-term administration of ethanol and moderate vitamin A supplementation in the rat. Hepatology 1983;3:1-11. doi: 10.1002/hep.1840030101.

[66] Keegan A, Martini R, Batey R. Ethanol-related liver injury in the rat: a model of steatosis, inflammation and pericentral fibrosis. J Hepatol 1995;23:591600. doi: 10.1016/0168-8278(95)80067-0.

[67] Rouach H, Fataccioli V, Gentil M, French SW, Morimoto M, Nordmann R. Effect of chronic ethanol feeding on lipid peroxidation and protein oxidation in relation to liver pathology. Hepatology 1997;25:351-355. doi: 10.1002 /hep.510250216.

[68] Bertola A, Mathews S, Ki SH, Wang H, Gao B. Mouse model of chronic and binge ethanol feeding (the NIAAA model). Nat Protoc 2013;8:627-637. doi: $10.1038 /$ nprot.2013.032.

[69] Chalasani N, Younossi Z, Lavine JE, Diehl AM, Brunt EM, Cusi K, et al. The diagnosis and management of non-alcoholic fatty liver disease: practice guideline by the American Gastroenterological Association, American Association for the Study of Liver Diseases, and American College of Gastroenterology. Gastroenterology 2012;142:1592-1609. doi: 10.1053 /j.gastro.2012.04.001.

[70] Kucera O, Cervinkova Z. Experimental models of non-alcoholic fatty liver disease in rats. World J Gastroenterol 2014;20:8364-8376. doi: 10.3748/ wjg.v20.i26.8364.

[71] Takahashi Y, Soejima Y, Fukusato T. Animal models of nonalcoholic fatty liver disease/nonalcoholic steatohepatitis. World J Gastroenterol 2012;18 2300-2308. doi: 10.3748/wjg.v18.i19.2300.

[72] Xu ZJ, Fan JG, Ding XD, Qiao L, Wang GL. Characterization of high-fat, dietinduced, non-alcoholic steatohepatitis with fibrosis in rats. Dig Dis Sci 2010;55:931-940. doi: 10.1007/s10620-009-0815-3. 
[73] Matsuzawa N, Takamura T, Kurita S, Misu H, Ota T, Ando $\mathrm{H}$, et al. Lipidinduced oxidative stress causes steatohepatitis in mice fed an atherogenic diet. Hepatology 2007; 46:1392-1403. doi: 10.1002/hep.21874.

[74] Tetri LH, Basaranoglu M, Brunt EM, Yerian LM, Neuschwander-Tetri BA. Severe NAFLD with hepatic necroinflammatory changes in mice fed trans fats and a high-fructose corn syrup equivalent. Am J Physiol Gastrointest Liver Physiol 2008;295:G987-G995. doi: 10.1152/ajpgi.90272.2008.

[75] Ghoshal AK. New insight into the biochemical pathology of liver in choline deficiency. Crit Rev Biochem Mol Biol 1995;30:263-273. doi: 10.3109 /10409239509083487

[76] Ip E, Farrell G, Hall P, Robertson G, Leclercq I. Administration of the potent PPARalpha agonist, $W y-14,643$, reverses nutritional fibrosis and steatohepatitis in mice. Hepatology 2004;39:1286-1296. doi: 10.1002/hep.20170.

[77] Kirsch R, Clarkson V, Shephard EG, Marais DA, Jaffer MA, Woodburne VE, et al. Rodent nutritional model of non-alcoholic steatohepatitis: species, strain and sex difference studies. J Gastroenterol Hepatol 2003;18:12721282. doi: 10.1046/j.1440-1746.2003.03198.x.

[78] Rinella ME, Green RM. The methionine-choline deficient dietary model of steatohepatitis does not exhibit insulin resistance. J Hepatol 2004;40:4751. doi: 10.1016/j.jhep.2003.09.020.

[79] Leclercq IA, Lebrun VA, Starkel P, Horsmans YJ. Intrahepatic insulin resistance in a murine model of steatohepatitis: effect of PPARgamma agonist pioglitazone. Lab Invest 2007;87:56-65. doi: 10.1038/labinvest. 3700489 .

[80] Kodama Y, Kisseleva T, Iwaisako K, Miura K, Taura K, de MS, et al. c-Jun Nterminal kinase-1 from hematopoietic cells mediates progression from hepatic steatosis to steatohepatitis and fibrosis in mice. Gastroenterology 2009;137:1467-1477. doi: 10.1053/j.gastro.2009.06.045

[81] Larter CZ, Yeh MM. Animal models of NASH: getting both pathology and metabolic context right. J Gastroenterol Hepatol 2008;23:1635-1648. doi: 10.1111/j.1440-1746.2008.05543.x.

[82] Shimomura I, Hammer RE, Richardson JA, Ikemoto S, Bashmakov Y, Goldstein $\mathrm{JL}$, et al. Insulin resistance and diabetes mellitus in transgenic mice expressing nuclear SREBP-1c in adipose tissue: model for congenital generalized lipodystrophy. Genes Dev 1998;12:3182-3194. doi: 10.1101 /gad.12.20.3182.

[83] Nakayama $\mathrm{H}$, Otabe $\mathrm{S}$, Ueno $\mathrm{T}$, Hirota $\mathrm{N}$, Yuan $\mathrm{X}$, Fukutani $\mathrm{T}$, et al. Transgenic mice expressing nuclear sterol regulatory element-binding protein $1 \mathrm{c}$ in adipose tissue exhibit liver histology similar to nonalcoholic steatohepatitis. Metabolism 2007;56:470-475. doi: 10.1016/j.metabol.2006.11.004.

[84] Stiles B, Wang Y, Stahl A, Bassilian S, Lee WP, Kim Y], et al. Liver-specific deletion of negative regulator Pten results in fatty liver and insulin hypersensitivity [corrected]. Proc Natl Acad Sci USA 2004;101:20822087. doi: 10.1073/pnas.0308617100.

[85] Horie Y, Suzuki A, Kataoka E, Sasaki T, Hamada K, Sasaki J, et al. Hepatocyte-specific Pten deficiency results in steatohepatitis and hepatocellular carcinomas. J Clin Invest 2004;113:1774-1783. doi: 10.1172 /JCI20513.

[86] Kanuri G, Bergheim I. In Vitro and in Vivo Models of Non-Alcoholic Fatty Liver Disease (NAFLD). Int J Mol Sci 2013;14:11963-11980.

[87] Gupte AA, Liu JZ, Ren Y, Minze LJ, Wiles JR, Collins AR, et al. Rosiglitazone attenuates age- and diet-associated nonalcoholic steatohepatitis in male low-density lipoprotein receptor knockout mice. Hepatology 2010;52: 2001-2011. doi: 10.1002/hep.23941.

[88] Yamashita T, Murakami T, Iida M, Kuwajima M, Shima K. Leptin receptor of Zucker fatty rat performs reduced signal transduction. Diabetes 1997;46: 1077-1080. doi: 10.2337/diab.46.6.1077.

[89] Yang SQ, Lin HZ, Lane MD, Clemens M, Diehl AM. Obesity increases sensitivity to endotoxin liver injury: implications for the pathogenesis of steatohepatitis. Proc Natl Acad Sci USA 1997;94:2557-2562. doi: 10.1073/pnas.94.6.2557.

[90] Carmiel-Haggai M, Cederbaum AI, Nieto N. A high-fat diet leads to the progression of non-alcoholic fatty liver disease in obese rats. FASEB J 2005; 19:136-138.

[91] Arsov T, Silva DG, O’Bryan MK, Sainsbury A, Lee NJ, Kennedy C, et al. Fat aussie-a new Alstrom syndrome mouse showing a critical role for ALMS1 in obesity, diabetes, and spermatogenesis. Mol Endocrinol 2006;20:16101622. doi: 10.1210/me.2005-0494.

[92] Arsov T, Larter CZ, Nolan C], Petrovsky N, Goodnow CC, Teoh NC, et al. Adaptive failure to high-fat diet characterizes steatohepatitis in Alms 1 mutant mice. Biochem Biophys Res Commun 2006;342:1152-1159. doi: 10.1016/j.bbrc.2006.02.032.

[93] Hayashi H, Sakai T. Animal models for the study of liver fibrosis: new insights from knockout mouse models. Am J Physiol Gastrointest Liver Physiol 2011;300:G729-G738. doi: 10.1152/ajpgi.00013.2011.

[94] Kanno K, Tazuma S, Chayama K. AT1A-deficient mice show less severe progression of liver fibrosis induced by $\mathrm{CCl}(4)$. Biochem Biophys Res Commun 2003;308:177-183. doi: 10.1016/S0006-291X(03)01357-3.
[95] Czochra P, Klopcic B, Meyer E, Herkel J, Garcia-Lazaro JF, Thieringer F, et al Liver fibrosis induced by hepatic overexpression of PDGF-B in transgenic mice. J Hepatol 2006;45:419-428. doi: 10.1016/j.jhep.2006.04.010.

[96] Sanderson N, Factor V, Nagy P, Kopp J, Kondaiah P, Wakefield L, et al. Hepatic expression of mature transforming growth factor beta 1 in transgenic mice results in multiple tissue lesions. Proc Natl Acad Sci USA 1995;92:2572-2576. doi: 10.1073/pnas.92.7.2572.

[97] Nevzorova YA, Hu W, Cubero FJ, Haas U, Freimuth J, Tacke F, et al. Overexpression of c-myc in hepatocytes promotes activation of hepatic stellate cells and facilitates the onset of liver fibrosis. Biochim Biophys Acta 2013;1832:1765-1775. doi: 10.1016/j.bbadis.2013.06.001.

[98] Mannaerts I, Schroyen B, Verhulst S, Van LL, Schuit F, Nyssen M, et al. Gene expression profiling of early hepatic stellate cell activation reveals a role for Igfbp3 in cell migration. PloS One 2013;8:e84071. doi: 10.1371/journal .pone.0084071.

[99] de MS, Seki E, Uchinami H, Kluwe J, Zhang Y, Brenner DA, et al. Gene expression profiles during hepatic stellate cell activation in culture and in vivo. Gastroenterology 2007;132:1937-1946. doi: 10.1053/j.gastro .2007.02.033.

[100] Sancho-Bru P, Bataller R, Gasull X, Colmenero J, Khurdayan V, Gual A, et al. Genomic and functional characterization of stellate cells isolated from human cirrhotic livers. J Hepatol 2005;43:272-282. doi: 10.1016 /j.jhep.2005.02.035.

[101] Hernandez-Gea V, Ghiassi-Nejad Z, Rozenfeld R, Gordon R, Fiel MI, Yue Z, et al. Autophagy releases lipid that promotes fibrogenesis by activated hepatic stellate cells in mice and in human tissues. Gastroenterology 2012 ; 142:938-946. doi: 10.1053/j.gastro.2011.12.044.

[102] Dickins RA, McJunkin K, Hernando E, Premsrirut PK, Krizhanovsky V, Burgess DJ, et al. Tissue-specific and reversible RNA interference in transgenic mice. Nat Genet 2007;39:914-921. doi: 10.1038/ng2045.

[103] Krizhanovsky V, Yon M, Dickins RA, Hearn S, Simon J, Miething C, et al. Senescence of activated stellate cells limits liver fibrosis. Cell 2008;134: 657-667. doi: 10.1016/j.cell.2008.06.049.

[104] Puche JE, Lee YA, Jiao J, Aloman C, Fiel MI, Munoz U, et al. A novel murine model to deplete hepatic stellate cells uncovers their role in amplifying liver damage in mice. Hepatology 2013;57:339-350. doi: 10.1002/hep.26053.

[105] Mederacke I, Hsu CC, Troeger JS, Huebener P, Mu X, Dapito DH, et al. Fate tracing reveals hepatic stellate cells as dominant contributors to liver fibrosis independent of its aetiology. Nat Commun 2013;4:2823. doi: $10.1038 /$ ncomms3823.

[106] Taura K, Miura K, Iwaisako K, Osterreicher CH, Kodama Y, PenzOsterreicher $M$, et al. Hepatocytes do not undergo epithelial-mesenchyma transition in liver fibrosis in mice. Hepatology 2010;51:1027-1036. doi: 10.1002/hep.23368.

[107] Chu AS, Diaz R, Hui JJ, Yanger K, Zong Y, Alpini G, et al. Lineage tracing demonstrates no evidence of cholangiocyte epithelial-to-mesenchymal transition in murine models of hepatic fibrosis. Hepatology 2011;53: 1685-1695. doi: 10.1002/hep. 24206.

[108] Friedman SL. Mechanisms of hepatic fibrogenesis. Gastroenterology 2008; 134:1655-1669. doi: 10.1053/j.gastro.2008.03.003.

[109] Kisseleva T, Cong M, Paik Y, Scholten D, Jiang C, Benner C, et al. Myofibroblasts revert to an inactive phenotype during regression of liver fibrosis. Proc Natl Acad Sci USA 2012;109:9448-9453. doi: 10.1073 /pnas.1201840109.

[110] Issa R, Zhou X, Trim N, Millward-Sadler H, Krane S, Benyon C, et al. Mutation in collagen- 1 that confers resistance to the action of collagenase results in failure of recovery from $\mathrm{CCl} 4$-induced liver fibrosis, persistence of activated hepatic stellate cells, and diminished hepatocyte regeneration. FASEB J 2003;17:47-49.

[111] Xue W, Chen S, Yin H, Tammela T, Papagiannakopoulos T, Joshi NS, et al. CRISPR-mediated direct mutation of cancer genes in the mouse liver Nature 2014;514:380-384. doi: 10.1038/nature13589.

[112] Poelstra K, Prakash J, Beljaars L. Drug targeting to the diseased liver. J Control Release 2012;161:188-197. doi: 10.1016/j.jconrel.2012 .02 .011 .

[113] Sato Y, Murase K, Kato J, Kobune M, Sato T, Kawano Y, et al. Resolution of liver cirrhosis using vitamin A-coupled liposomes to deliver siRNA against a collagen-specific chaperone. Nat Biotechnol 2008;26:431-442. doi: $10.1038 /$ nbt1396.

[114] Narmada BC, Kang Y, Venkatraman L, Peng Q, Sakban RB, Nugraha B, et al. Hepatic stellate cell-targeted delivery of hepatocyte growth factor transgene via bile duct infusion enhances its expression at fibrotic foci to regress dimethylnitrosamine-induced liver fibrosis. Hum Gene Ther 2013;24:508519. doi: 10.1089/hum.2012.158.

[115] Bansal R, Prakash J, Post E, Beljaars L, Schuppan D, Poelstra K. Nove engineered targeted interferon-gamma blocks hepatic fibrogenesis in mice. Hepatology 2011;54:586-596. doi: 10.1002/hep.24395.

[116] Grompe M, Strom S. Mice with human livers. Gastroenterology 2013;145: 1209-1214. doi: 10.1053/j.gastro.2013.09.009. 
[117] Bility MT, Li F, Cheng L, Su L. Liver immune-pathogenesis and therapy of human liver tropic virus infection in humanized mouse models. J Gastroenterol Hepatol 2013;28:120-124. doi: 10.1111/jgh.12092.

[118] Bility MT, Cheng L, Zhang Z, Luan Y, Li F, Chi L, et al. Hepatitis B virus infection and immunopathogenesis in a humanized mouse model: induction of human-specific liver fibrosis and M2-like macrophages. PLoS Pathog 2014;10:e1004032. doi: 10.1371/journal.ppat.1004032.

[119] Jonker AM, Dijkhuis FW, Hardonk MJ, Moerkerk P, Ten KJ, Grond J. Immunohistochemical study of hepatic fibrosis induced in rats by multiple galactosamine injections. Hepatology 1994;19:775-781. doi: 10.1002 /hep.1840190334.

[120] Matsumoto M, Hada N, Sakamaki Y, Uno A, Shiga T, Tanaka C, et al. An improved mouse model that rapidly develops fibrosis in non-alcoholic steatohepatitis. Int J Exp Pathol 2013;94:93-103. doi: 10.1111/iep.12008.

[121] Domenicali M, Caraceni P, Giannone F, Baldassarre M, Lucchetti G, Quarta C, et al. A novel model of $\mathrm{CCl} 4$-induced cirrhosis with ascites in the mouse. J Hepatol 2009;51:991-999. doi: 10.1016/j.jhep.2009.09.008.
[122] Jimenez W, Claria J, Arroyo V, Rodes J. Carbon tetrachloride induced cirrhosis in rats: a useful tool for investigating the pathogenesis of ascites in chronic liver disease. J Gastroenterol Hepatol 1992;7:90-97. doi: 10.1111 /j.1440-1746.1992.tb00940.x.

[123] Manibusan MK, Odin M, Eastmond DA. Postulated carbon tetrachloride mode of action: a review. J Environ Sci Health C Environ Carcinog Ecotoxicol Rev 2007;25:185-209. doi: 10.1080/10590500701569398.

[124] Popov Y, Patsenker E, Bauer M, Niedobitek E, Schulze-Krebs A, Schuppan D. Halofuginone induces matrix metalloproteinases in rat hepatic stellate cells via activation of p38 and NFkappaB. J Biol Chem 2006;281:15090-15098. doi: $10.1074 /$ jbc.M600030200.

[125] Wang T, Shankar K, Ronis MJ, Mehendale HM. Potentiation of thioacetamide liver injury in diabetic rats is due to induced CYP2E1. J Pharmacol Exp Ther 2000;294:473-479.

[126] Heindryckx F, Colle I, Van VH. Experimental mouse models for hepatocellular carcinoma research. Int J Exp Pathol 2009;90:367-386. doi: 10.1111/ j.1365-2613.2009.00656.x. 